Supplement of Biogeosciences, 12, 7185-7208, 2015

http://www.biogeosciences.net/12/7185/2015/

doi:10.5194/bg-12-7185-2015-supplement

(C) Author(s) 2015. CC Attribution 3.0 License.

(c) (i)

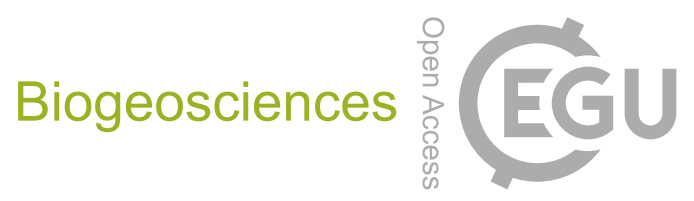

Supplement of

\title{
Using satellite data to improve the leaf phenology of a global terrestrial biosphere model
}

N. MacBean et al.

Correspondence to: N. MacBean (nlmacbean@gmail.com)

The copyright of individual parts of the supplement might differ from the CC-BY 3.0 licence. 
1

\section{Supplementary Material}

2

3
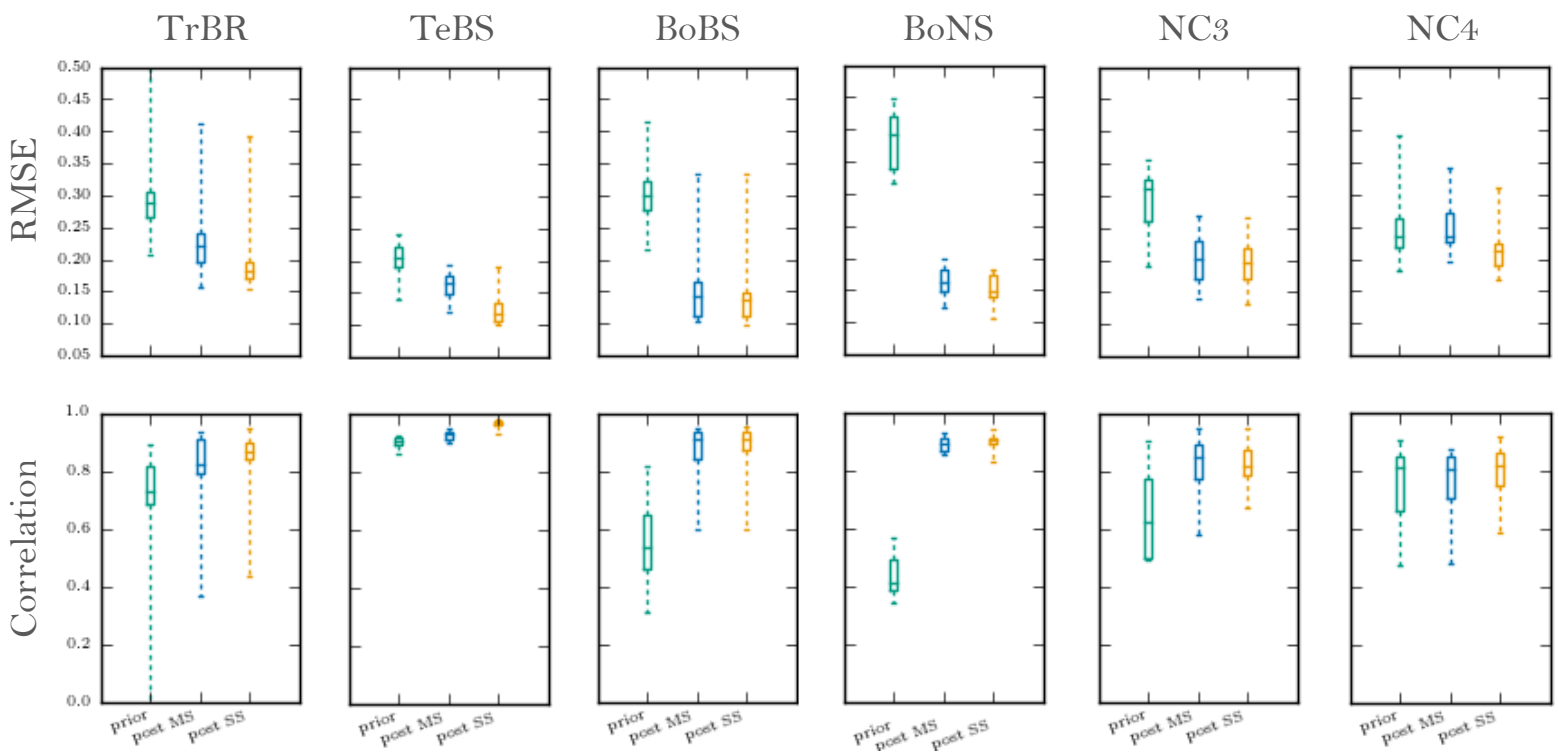

5 Figure S1. Box and whisker plots showing the spread in the prior and single-site (SS) and

6 multi-site (MS) posterior RMSE and R between the normalized modeled fAPAR and MODIS

7 NDVI data across all sites for all optimized PFTs. The middle line shows the median, the

8 lower and upper edges of the box correspond to the $25^{\text {th }}$ and $75^{\text {th }}$ percentile respectively, and

9 the range of the whiskers corresponds to the maximum and minimum RMSE and R. 

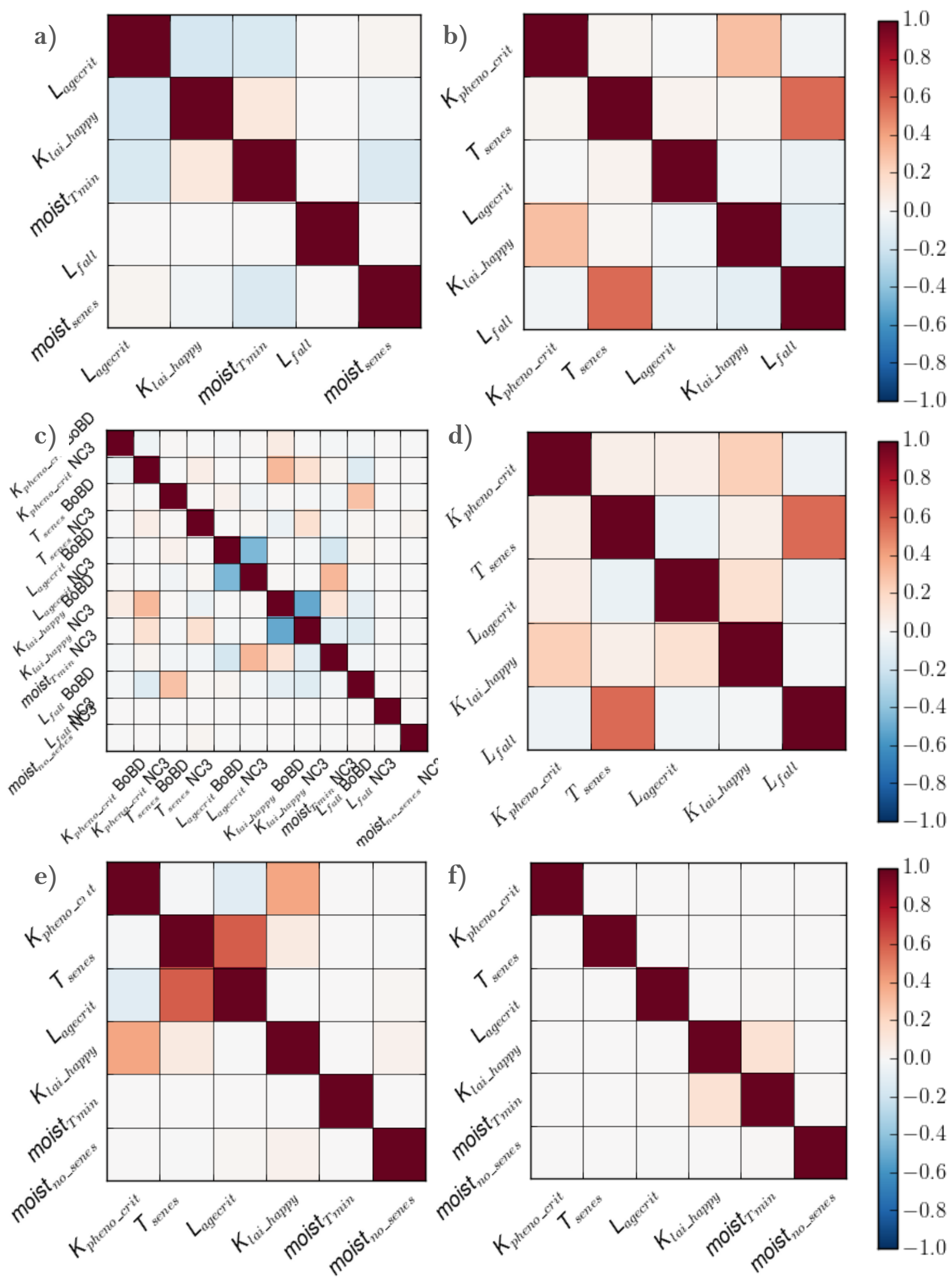

2 Figure S2. Parameter posterior covariance matrices for MS optimization for the a) $\operatorname{TrBR}$; $b$ )

3 TeBD; c) BoBD; d) BoND; e) NC3; f) NC4 PFTs. Note in c) that BoBD sites contained 
1 significant fraction of NC3 grasses and therefore the parameters were optimized for both 2 PFTs (see Section 3.3.3).

3

4

5 